\title{
EXTENSION OF A THEOREM OF A. WINTNER
}

L. SUYEMOTO AND P. WALTMAN

In [1] A. Wintner established the following theorem.

TheOREM 1. The differential equation

(1)

$$
y^{\prime \prime}+f(x) y=0
$$

cannot have an $\left(L^{2}\right)$-solution if

$$
\int_{0}^{\infty} x^{3}|f(x)|^{2} d x<\infty
$$

(where $\lim \sup _{x \rightarrow \infty}|f(x)| \neq 0$ is allowed).

In this note, Theorem 1 will be extended to the more general equation

$$
y^{\prime \prime}+f(x) y^{p}=0 .
$$

THEOREM 2. If (2) holds, and $p \geqq 1$, then (3) has no ( $\left.L^{2 p}\right)$-solutions.

For $p=1$ this reduces to the result of Wintner. First we establish two propositions.

(A) If (3) has an ( $\left.L^{2 p}\right)$-solution then $y^{\prime}(x) \rightarrow 0$ and $y(x) \rightarrow 0$ as $x \rightarrow \infty$.

The proof of (A) follows that given for similar conclusions in [1].

(B) The existence of an $\left(L^{2 p}\right)$-solution of (3) implies the existence of an $\left(L^{2}\right)$ solution.

Integrating (3) twice and using (A)

$$
|y(x)| \leqq \int_{x}^{\infty}\left[\int_{u}^{\infty}|f(v)||y(v)|^{p} d v\right] d u \leqq \int_{x}^{\infty} u|f(u)||y(u)|^{p} d u
$$

Hence

$$
\begin{aligned}
\int_{0}^{\infty}|y(x)|^{2} d x & \leqq \int_{0}^{\infty}\left[\int_{x}^{\infty} u|f(u)||y(u)|^{p} d u\right]^{2} d x \\
& \leqq \int_{0}^{\infty}\left[\int_{x}^{\infty} u^{2}|f(u)|^{2} d u\right]\left[\int_{x}^{\infty}|y(u)|^{2 p} d u\right] d x \\
& \leqq\left[\int_{0}^{\infty}|y(x)|^{2 p} d x\right]\left[\int_{0}^{\infty} x^{3}|f(x)|^{2} d x\right]
\end{aligned}
$$

Both integrals on the right converge, which establishes (B).

Received by the editors September 17, 1962. 
Now suppose (2) holds and (3) has an $\left(L^{2 p}\right)$-solution for $p \geqq 1$. By (A) there exists a $T$ such that $|y(t)|<1$ for $t>T$; hence $|y(t)|^{2}$ $\geqq|y(t)|^{2 p}$ for $p \geqq 1$ and $t>T$. Proceeding as in (4) with such a $t$ as lower limit gives

$$
\begin{aligned}
\int_{t}^{\infty}|y(x)|^{2} d x & \leqq\left[\int_{t}^{\infty}|y(x)|^{2 p} d x\right]\left[\int_{t}^{\infty} x^{3}|f(x)|^{2} d x\right] \\
& \leqq\left[\int_{t}^{\infty}|y(x)|^{2} d x\right]\left[\int_{t}^{\infty} x^{3}|f(x)|^{2} d x\right] .
\end{aligned}
$$

Since $\int_{t}^{\infty}|y(x)|^{2} d x>0$, it follows that

$$
\int_{t}^{\infty} x^{3}|f(x)|^{2} d x>1
$$

contradicting (2) and establishing the theorem.

\section{BIBLIOGRAPHY}

1. A. Wintner, $A$ criterion for the non-existence of ( $\left.\mathrm{L}^{2}\right)$-solutions of a nonoscillatory differential equation, J. London Math. Soc. 25 (1950), 347-351.

The Mitre Corporation and Sandia Corporation 